\title{
Autoimmune and Neoplastic Thyroid Diseases Associated with Hepatitis C Chronic Infection
}

\author{
Poupak Fallahi, ${ }^{1}$ Silvia Martina Ferrari, ${ }^{1}$ Ugo Politti, ${ }^{1}$ Dilia Giuggioli, \\ Clodoveo Ferri, ${ }^{2}$ and Alessandro Antonelli ${ }^{1}$ \\ ${ }^{1}$ Department of Clinical and Experimental Medicine, University of Pisa, Via Savi 10, 56126 Pisa, Italy \\ ${ }^{2}$ Department of Medical, Surgical, Maternal, Pediatric and Adult Sciences, University of Modena and Reggio Emilia, \\ Via del Pozzo 71, 41100 Modena, Italy \\ Correspondence should be addressed to Alessandro Antonelli; alessandro.antonelli@med.unipi.it
}

Received 1 August 2014; Accepted 24 September 2014; Published 13 October 2014

Academic Editor: Marek Bolanowski

Copyright (C) 2014 Poupak Fallahi et al. This is an open access article distributed under the Creative Commons Attribution License, which permits unrestricted use, distribution, and reproduction in any medium, provided the original work is properly cited.

\begin{abstract}
Frequently, patients with hepatitis $\mathrm{C}$ virus $(\mathrm{HCV})$ chronic infection have high levels of serum anti-thyroperoxidase and/or antithyroglobulin autoantibodies, ultrasonographic signs of chronic autoimmune thyroiditis, and subclinical hypothyroidism, in female gender versus healthy controls, or hepatitis B virus infected patients. In patients with "HCV-associated mixed cryoglobulinemia" $(\mathrm{MC}+\mathrm{HCV})$, a higher prevalence of thyroid autoimmune disorders was shown not only compared to controls, but also versus HCV patients without cryoglobulinemia. Patients with MC + HCV or HCV chronic infection show a higher prevalence of papillary thyroid cancer than controls, in particular in patients with autoimmune thyroiditis. Patients with HCV chronic infection, or with $\mathrm{MC}+\mathrm{HCV}$, in presence of autoimmune thyroiditis, show higher serum levels of T-helper (Th)1 (C-X-C motif) ligand 10 (CXCL10) chemokine, but normal levels of Th2 (C-C motif) ligand 2 chemokine, than patients without thyroiditis. HCV thyroid infection could act by upregulating CXCL10 gene expression and secretion in thyrocytes recruiting Th1 lymphocytes that secrete interferon$\gamma$ and tumor necrosis factor- $\alpha$. These cytokines might induce a further CXCL10 secretion by thyrocytes, thus perpetuating the immune cascade, which may lead to the appearance of autoimmune thyroid disorders in genetically predisposed subjects. A careful monitoring of thyroid function, particularly where nodules occur, is recommended in HCV patients.
\end{abstract}

\section{Introduction}

About 130-170 million people worldwide have been infected by hepatitis $\mathrm{C}$ virus (HCV) [1]. Hepatocytes represent the major site of viral replication, and the replication of HCV is present in extrahepatic tissues and peripheral blood mononuclear cells [2].

Previous studies have shown that $38-76 \%$ of patients with chronic HCV infection develop at least one extrahepatic manifestation (EHM) [3, 4].

An association between HCV and mixed cryoglobulinemia (MC) was first described; subsequently, the involvement of many organs and systems was reported (kidney, skin, eyes, joints, and nervous system). The infected extrahepatic tissues might act as a reservoir for HCV [5] and play a role in both HCV persistence and reactivation of infection. $\mathrm{HCV}$, as an etiological agent replicating and expressing viral proteins in extrahepatic tissues itself, contributes to EHM associated with chronic HCV infection. An important feature of $\mathrm{HCV}$ is that the virus avoids immune elimination; a consequence is chronic infection and an accumulation of circulating immunocomplexes and autoimmune phenomena [6-8], as recently Cheng et al. have demonstrated in their study among 297 Chinese patients [9].

These EHM mainly include autoimmune disorders [1012] such as MC [13, 14] and Sjogren's syndrome and endocrinological diseases as autoimmune thyroid disorders (AITD) and type 2 diabetes [15-17].

\section{Autoimmune Thyroiditis}

Hashimoto's thyroiditis or autoimmune chronic thyroiditis (AT) is among the most common thyroid diseases. AT is the most widespread thyroiditis form and its prevalence is 
definitely more frequent in female gender and in the elderly. The incidence in female gender is of 3,5 cases/1000 subjects per year, while in men it is lower $(0,8$ cases $/ 1000$ persons per year): there is a remarkable variability in different geographic areas [18].

AT is an organ-specific autoimmune disease, morphologically characterized by a chronic lymphocytes infiltration of thyroid and the presence of circulating autoantibodies such as antiperoxidase (AbTPO) and antithyroglobulin (AbTg). The inflammatory process leads to a follicular destruction; indeed, AT is the most common cause of hypothyroidism in areas of iodine sufficiency [19].

Occasionally, thyroid stimulating hormone (TSH) receptor blocking antibodies can be responsible of an atrophic form of AT; more rarely, anti-TSH receptor stimulating antibodies can cause a transient form of hyperthyroidism (hashitoxicosis) [20].

Risk factors associated with AT are numerous [21-24].

(a) Age: the prevalence of disease tends to increase with age.

(b) Genetic: a significant association between Hashimoto's thyroiditis and some histocompatibility antigens (HLA-DR, HLA-DR5, and some DQ alleles) is demonstrated. Many other susceptibility genes have been associated with AT; for example, specific CTLA4 gene polymorphisms are linked to a possible development of antithyroid antibodies [25].

(c) Iodine: an increased AT prevalence is observed in areas of iodine sufficiency, compared with iodinedeficient areas [26, 27].

(d) Selenium: a selenium deficit is linked to a higher AT prevalence [28].

(e) Irradiation: AT occurs more frequently after the exposure to low doses of radiations [26].

(f) Cytokine: the treatment with Interferon- (IFN-) $\alpha$, or with Interleukin- (IL-) 2, can promote the onset of AT in predisposed patients [29].

(g) Infections: it was seen that several viral infections can predispose to an AT in animals. Moreover, different studies tried to associate AT with viral infections in humans with conflicting results [30-33].

\section{Chronic HCV (CHC) Infection and Thyroid}

3.1. CHC Infection and Thyroid Autoimmunity. In a first study, Tran et al. report two cases of Hashimoto's thyroiditis associated with chronic active $\mathrm{HCV}$ infection, suggesting that $\mathrm{HCV}$ infection might be involved in the appearance of AT $[34,35]$.

The prevalence of HCV infection in patients with different thyroid disorders has been evaluated by several studies with conflicting results. Duclos-Vallée et al. evaluated the prevalence of HCV infection in 200 patients with thyroid diseases; among 50 patients with simple goiter, none were anti-HCV-positive; among 50 individuals with goiter, 2 were positive; among 5 individuals with myxedema, 2 were positive; among 50 patients with Hashimoto's thyroiditis, 12 were positive. These results suggested that $\mathrm{HCV}$ infection might be associated with AT [36]. Recently, Yang et al. compared 462 persons with positive AbTPO and/or AbTg to 360 persons with antibody negativity and no difference in the prevalence of anti-HCV positivity between the 2 groups (1.3\% versus $0.53 \% ; P>0.05)$ was found [37]. In a study conducted by Marconcini et al., $66 \mathrm{HCV}+$ patients were evaluated and AbTPOs were detected in 4/54 (7.4\%) of the patients, whereas AbTgs were detected in none of the patients (0/48) [38].

Conflicting results have been reported from earlier studies of patients with $\mathrm{CHC}$, with some supporting an association of HCV infection with AITD [39-47] and others not $[48,49]$.

However, some of the earlier studies were negative because of the lack of control for factors which may affect the development of thyroid autoimmunity, such as iodine intake [50].

Indeed, the largest study about HCV and thyroiditis, in which iodine deficiency was evaluated, demonstrated that both hypothyroidism and thyroid autoimmunity were significantly more common in patients with HCV compared to controls [41].

The prevalence of thyroid disorders in 630 consecutive patients with chronic hepatitis due to $\mathrm{HCV}$ infection was investigated; all patients were free of cirrhosis and hepatocarcinoma and were not on interferon treatment. Three control groups were included: (a) 389 subjects from an iodine-deficient area, (b) 268 persons living in an area of iodine sufficiency, and (c) 86 patients $>40$ years of age with chronic hepatitis $\mathrm{B}$. Levels of thyroid-stimulating hormone (TSH), free T4 (FT4), and free T3 (FT3), as well as AbTgs and AbTPOs, were measured. Mean TSH levels were higher $(P=0.001)$ and FT3 and FT4 levels were lower $(P<0.0001)$ in patients with $\mathrm{CHC}$ than in all other groups. Patients with $\mathrm{CHC}$ were more likely to have hypothyroidism $(13 \%$ $(n=82))$, AbTgs $(17 \%(n=108))$, and AbTPOs $(21 \%$ $(n=132))$ than were any of the other groups. The results of this study suggested that both hypothyroidism and thyroid autoimmunity are more common in patients with $\mathrm{CHC}$, even in the absence of cirrhosis, hepatocellular carcinoma, or interferon treatment, than in $\mathrm{HCV}$-negative controls or in patients with chronic hepatitis B infection [41].

Evidence for this association also came from a study that reported a higher prevalence of hypothyroidism and AbTgs in untreated children with $\mathrm{CHC}$ compared to healthy non-HCV infected controls [51]. In most studies, examining the frequency of thyroid disorders in patients with HCV, approximately $10-15 \%$ of the patients had positive thyroid antibodies before the beginning of the therapy with IFN [5258]. Moreover, pooling of data from controlled studies on $\mathrm{HCV}$ infection and thyroid autoimmunity demonstrated a significant increase in the risk of thyroiditis in HCV patients [59]. A large study which included 146394 patients infected with HCV confirmed these results showing a significant increased risk for thyroiditis [60]. This was a retrospective cohort study of users of US Veterans Affairs health care facilities from 1997 to 2004, which included $146394 \mathrm{CHC}$ patients 
who had at least 2 visits and 572293 patients uninfected with $\mathrm{HCV}$. The thyroiditis risk was significantly increased in $\mathrm{HCV}$ patients. Since $97 \%$ of HCV patients were men and it is well known that male gender has a lower risk of thyroiditis than female, this result is particularly interesting [60].

The presence of higher risk of AT in female gender increased circulating levels of AbTPOs and increased risk of hypothyroidism in female gender and AbTPO-positive subjects characterized the pattern of thyroid disorders observed in HCV infection $[59,61,62]$.

Despite their remarkable therapeutic efficacy, IFN- $\alpha$ adverse effects are well-known, from influenza-like symptoms to hematologic effects, neuropsychiatric symptoms, and thyroid diseases [63]. In particular, previous studies showed that female gender is one of the most common risk factors that predict the development of AITD during interferon therapy $[64,65]$. An association between IFN- $\alpha$ and thyroid disease was recognized as early as 1985 in patients who have been treated with IFN- $\alpha$ for breast cancer [66]. Later, several cases have reported the possible association between thyroid disease and IFN- $\alpha$ [67]. Different forms of IFN induced thyroid autoimmunity have been identified, such as GD, thyroiditis, and subclinical hypothyroidism [68]. Graves' hyperthyroidism is the less common type, because only $20-25 \%$ of all patients with IFN-related thyrotoxicosis are linked to Graves' disease (GD) induced by circulating thyroid receptor antibodies (TRAb) $[69,70]$.

Interferon induced thyroiditis (IIT) can be divided into two main groups: autoimmune type and nonautoimmune type [71]. The former can manifest as HT and GD and sometimes may be related to the production of thyroid autoantibodies without clinical disease.

Another interesting classification of interferon induced hyperthyroidism has been proposed by Czarnywojtek et al. [72] (in comparison with amiodarone induced thyrotoxicosis (AIT)): (I) type 1 , corresponding to type I amiodarone induced thyrotoxicosis (AIT): (a) GT without TAO and (b) GT with TAO (mild or severe); (II) type 2 destructive thyrotoxicosis, partially analogous to type II AIT: (a) asymptomatic: silent thyroiditis and (b) symptomatic; and (III) type 3 unknown aetiology, partial analogy to type III AITundefined or mixed.

The presence of thyroid autoantibodies before the initiation of IFN- $\alpha$ therapy is an important risk factor for the development of IIT. In HCV-positive individuals, the progression toward hypothyroidism, in thyroid autoantibodies positive patients who undergo IFN- $\alpha$ treatment, is often associated with an increase in antibody titers [73]. Furthermore, Prummel and Laurberg showed that positive pretreatment AbTPOs are an important risk factor for the development of thyroid dysfunction [74]. There is also an obvious link between female sex, old age, and genetic predisposition with the development of antibodies $[75,76]$.

3.2. Cryoglobulinemia and Thyroid Diseases. Few anecdotal studies evaluated AITD in patients with cryoglobulinemia $[77,78]$.

A case-control prospective study has been conducted to evaluate thyroid disorders in $93 \mathrm{MC}+\mathrm{HCV}$ patients, matched by sex and age ( \pm 2 years), to 93 patients with $\mathrm{CHC}$ without MC and 93 healthy (HCV-negative) controls from the local population $[79,80]$. The following thyroid autoimmune abnormalities were significantly more frequent in $\mathrm{MC}+\mathrm{HCV}$ patients than in HCV-negative controls: serum AbTPO levels (28\% versus 9\%), serum AbTPO and/or AbTg levels (31\% versus $12 \%)$, AT (35\% versus $16 \%$ ), and subclinical hypothyroidism (11\% versus $2 \%$ ). Serum AbTPOs were also significantly more frequent in $\mathrm{MC}+\mathrm{HCV}$ patients than in CHC controls (28\% versus $14 \%)$. A higher prevalence of thyroid disorders in patients with $\mathrm{MC}+\mathrm{HCV}$ not only with respect to controls, but also with respect to $\mathrm{HCV}$ patients without cryoglobulinemia was shown, suggesting a careful monitoring of thyroid function in these patients [80].

The presence of a higher risk of AT and hypothyroidism and increased circulating levels of AbTPO, in female gender, characterized the pattern of thyroid disorders observed in $\mathrm{MC}+\mathrm{HCV}$ infection, similarly to $\mathrm{HCV}$ patients without MC $[59,61]$.

3.3. CHC Infection and Thyroid Cancer. A high prevalence of papillary thyroid cancer (PTC) was first observed in 139 HCV patients (2.2\%), while no case was observed in 835 control subjects who were long-term residents of an iodinedeficient area [81], and it was subsequently confirmed in other studies $[82,83]$. Montella et al. have carried out a casecontrolled study on the different oncological pathologies. They screened 495 patients with different types of cancer: 114 cases of liver cancer, 41 of multiple myeloma, 111 of nonHodgkin's lymphomas, 130 of thyroid cancers, and 63 cases of Hodgkin's disease. The controls were 226 patients with no history of cancer. The relationship between each cancer and $\mathrm{HCV}$ infection was assessed by means of odds ratios (OR) and corresponding $95 \%$ confidence intervals.

Risks were greater for liver cancer $(\mathrm{OR}=32.9,95 \%$ CI 16.5-65.4, $P<0.0001)$, multiple myeloma $(\mathrm{OR}=4.5$, 95\% CI 1.9-10.7, $P=0.0004)$, and B-cell non-Hodgkin's lymphoma $(\mathrm{OR}=3.7,95 \%$ CI 1.9-7.4, $P=0.0001)$. For Hodgkin's disease, there was no significant association $(P=$ 0.3). An association between $\mathrm{HCV}$ and thyroid cancer was noted $(\mathrm{OR}=2.8,95 \%$ CI 1.2-6.3, $P=0.01)$ [83].

The prevalence of thyroid cancer was also investigated in a series of unselected $94 \mathrm{MC}+\mathrm{HCV}$ patients in comparison with a gender- and age-matched control group obtained from a sample of the general population (470 subjects). The prevalence of thyroid nodules was higher in control subjects than in $\mathrm{MC}+\mathrm{HCV}$ patients (65.3\% versus $54.8 \%$ ), even though not significantly. Two patients with PTC were found in the MC + HCV series, while no case was observed among controls $(P=0.001)$. Lymphocytic infiltration was observed in the thyroid tissue in both $\mathrm{MC}+\mathrm{HCV}$ patients with PTC [84]. Other studies have confirmed an association between AT and thyroid cancer $[85,86]$. Accordingly, features of AT were observed more frequently in $\mathrm{HCV}$ patients than in controls suggesting that AT may be a predisposing condition for thyroid cancer [87]. Since about $15-30 \%$ of $\mathrm{HCV}$ patients may show an aggressive disease, for example, lung metastases, difficult to treat $[88,89]$, the finding of an 
increased prevalence of thyroid cancer in these patients is clinically relevant [90].

3.4. Immunopathogenesis of HCV Infection and AITD. Several molecular mechanisms have been suggested for the association of $\mathrm{CHC}$ with AT: (a) molecular mimicry or cross-reactivity which may occur between viral antigens and thyroidal antigens [91], (b) heat shock proteins expression in thyroid gland [92], and (c) abnormal expression of MHC class II molecules by thyrocytes [93].

An increased expression of IFN- $\gamma$ and IFN- $\gamma$ inducible chemokines $[94,95]$, in particular (C-X-C motif) ligand 10 chemokine (CXCL10), has been shown in hepatocytes and in lymphocytes of HCV infected patients, directly related to the degree of inflammation and to an increase in circulating levels of IFN- $\gamma$ and CXCL10 [40, 96-103]. CXCL10 is one of chemokines with C-X-C motif. IP-10 activates specifically CXCR3 receptor that is a $G$ protein-coupled receptor with seven transmembrane domains mainly expressed in $\mathrm{T}$ activated lymphocytes, natural-killer cells (NKs), macrophages, and B cells $[104,105]$. Recent studies showed that CXCL10 expression in serum and/or tissue levels is increased in autoimmune organ-specific diseases [106], such as type 1 diabetes [107-109], or systemic rheumatological diseases like rheumatoid arthritis, systemic lupus erythematosus, systemic sclerosis $[97,110]$, sarcoidosis $[111,112]$, and psoriatic arthritis $[113,114]$.

High levels of CXCL10 are present in patients with AT, in particular in the presence of hypothyroidism, and an involvement of T-helper (Th)1 immune response in the induction of AT [97, 115-117], GD, and Graves' ophthalmopathy [97-100, 118] has been demonstrated, suggesting that intrathyroidal lymphocytes and/or thyrocytes may be the source of CXCL10 [119]. Furthermore, the presence of HCV in the thyroid of chronically infected patients has been recently shown $[120$, 121].

On the abovementioned bases, it has been speculated that HCV thyroid infection may act by upregulating CXCL10 gene expression and secretion in thyrocytes recruiting Thl lymphocytes that secrete IFN- $\gamma$ and tumor necrosis factor- (TNF) $\alpha$. These cytokines induce CXCL10 secretion by thyrocytes, thus perpetuating the immune cascade, which may lead to the appearance of AITD in genetically predisposed subjects [111] (Figure 1).

Recently, the finding of high serum levels of CXCL10 but normal levels of the prototype Th2 chemokine (C-C motif) ligand 2 (CCL2) in MC + HCV patients with AT, in comparison with patients without thyroiditis, has confirmed this hypothesis. These data suggest that the Th1 CXCL10 chemokine is specifically linked to the appearance of AT in these patients [122].

Serums CXCL10 and CCL2 were assayed in $60 \mathrm{MC}+$ $\mathrm{HCV}$ patients, in 45 patients with "MC with AT" (MC + $\mathrm{AT}$ ), and in controls (60 without (control 1) and 45 with AT (control 2)). CXCL10 was significantly higher in control 2 than in control $1(P<0.001)$, in MC than in control 1 , and in MC + AT than in controls 1 and 2 and MC $(P=0.002)$. A high CXCL10 level ( $>$ mean \pm SD control $1 ;>167 \mathrm{pg} / \mathrm{mL})$ was present in $7 \%$ of control 1, 21\% of control 2, $49 \%$ of MC,

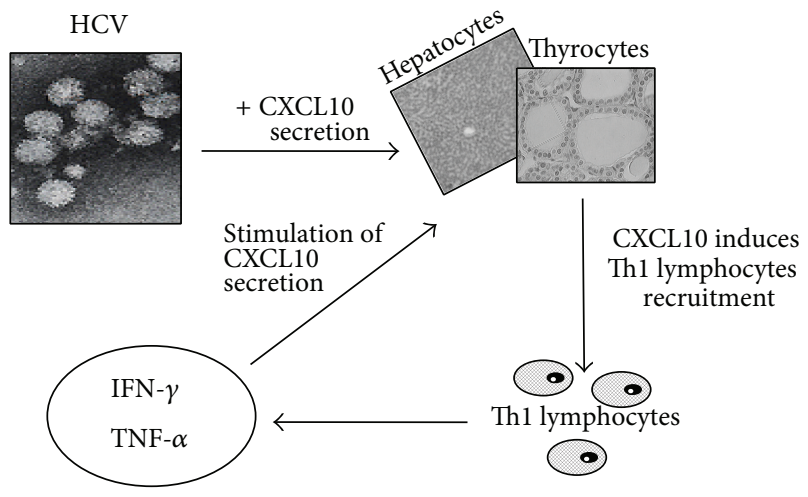

FIGURE 1: HCV thyroid infection may act by upregulating CXCL10 gene expression and secretion in thyrocytes recruiting Thl lymphocytes that secrete IFN- $\gamma$ and TNF- $\alpha$. These cytokines induce CXCL10 secretion by thyrocytes, thus perpetuating the immune cascade.

and $78 \%$ of MC + AT $(P<0.0001)$. CCL2 was significantly higher in $\mathrm{MC}$ and in $\mathrm{MC}+\mathrm{AT}$ than in control 1 or in control $2(P<0.01)$. A high CCL2 level (>mean \pm SD control 1; $>730 \mathrm{pg} / \mathrm{mL}$ ) was present in $2 \%$ of control $1,1 \%$ of control 2 , $18 \% \mathrm{MC}$, and $21 \%$ of MC + AT $(P<0.0001)[122]$.

Among the proinflammatory cytokines, IL-1 $\beta$ and TNF$\alpha$ were not associated with the presence of AT in $\mathrm{MC}+\mathrm{HCV}$ patients, while IL- 6 was modestly but significantly increased in patients with AT [5, 123-125].

On the whole, in agreement with what was observed in other autoimmune disorders [126-129], the above reported data underline the importance of the activation of the Th1 immunity in the initiation of AT in patients with MC + HCV.

\section{Conclusion}

In conclusion, the abovementioned results show a high prevalence of AITD in patients with CHC infection. The presence of a higher risk of AT in female gender, increased circulating levels of AbTPOs, and increased risk of hypothyroidism in female gender and AbTPO-positive subjects characterized the pattern of thyroid disorders observed in $\mathrm{HCV}$ infection. In HCV patients with thyroid cancer, thyroidectomy is required and, if appropriate, radioiodine treatment. Patients with HCV infection with AITD where nodules occurred and in fine needle aspiration biopsy without neoplastic processes do require careful observation.

\section{Conflict of Interests}

The authors declare that there is no conflict of interests regarding the publication of this paper.

\section{References}

[1] M. J. Alter, "Epidemiology of hepatitis C virus infection," World Journal of Gastroenterology, vol. 13, no. 17, pp. 2436-2441, 2007.

[2] J. T. Blackard, N. Kemmer, and K. E. Sherman, "Extrahepatic replication of $\mathrm{HCV}$ : insights into clinical manifestations and 
biological consequences," Hepatology, vol. 44, no. 1, pp. 15-22, 2006.

[3] D. V. Stefanova-Petrova, A. H. Tzvetanska, E. J. Naumova et al., "Chronic hepatitis $\mathrm{C}$ virus infection: prevalence of extrahepatic manifestations and association with cryoglobulinemia in Bulgarian patients," World Journal of Gastroenterology, vol. 13, no. 48, pp. 6518-6528, 2007.

[4] A. Galossi, R. Guarisco, L. Bellis, and C. Puoti, "Extrahepatic manifestations of chronic HCV infection," Journal of Gastrointestinal and Liver Diseases, vol. 16, no. 1, pp. 65-73, 2007.

[5] C. Ferri, A. Antonelli, M. T. Mascia et al., "B-cells and mixed cryoglobulinemia," Autoimmunity Reviews, vol. 7, no. 2, pp. 114120, 2007.

[6] C. Ferri, A. Antonelli, M. T. Mascia et al., "HCV-related autoimmune and neoplastic disorders: the HCV syndrome," Digestive and Liver Disease, vol. 39, no. 1, pp. S13-S21, 2007.

[7] S. M. Ferrari, P. Fallahi, C. Mancusi et al., "HCV-related autoimmune disorders in HCV chronic infection," La Clinica Terapeutica, vol. 164, no. 4, pp. e305-e312, 2013.

[8] P. Fallahi, S. M. Ferrari, D. Giuggioli et al., "Mixed cryoglobulinemia and thyroid autoimmune disorders," Clinica Terapeutica, vol. 164, no. 4, pp. e337-e341, 2013.

[9] Z. J. Cheng, B. T. Zhou, X. C. Shi et al., "Extrahepatic manifestations of chronic hepatitis C virus infection: 297 cases from a tertiary medical center in Beijing, China," Chinese Medical Journal, vol. 127, no. 7, pp. 1206-1210, 2014.

[10] J. T. Blackard, L. Kong, A. K. Huber, and Y. Tomer, "Hepatitis C virus infection of a thyroid cell line: implications for pathogenesis of hepatitis C virus and thyroiditis," Thyroid, vol. 23, no. 7, pp. 863-870, 2013.

[11] C. Palazzi, D. Buskila, S. D’ Angelo, E. D’ Amico, and I. Olivieri, "Autoantibodies in patients with chronic hepatitis C virus infection: pitfalls for the diagnosis of rheumatic diseases," Autoimmunity Reviews, vol. 11, no. 9, pp. 659-663, 2012.

[12] D. Saadoun, D. A. Landau, L. H. Calabrese, and P. P. Cacoub, "Hepatitis C-associated mixed cryoglobulinaemia: a crossroad between autoimmunity and lymphoproliferation," Rheumatology, vol. 46, no. 8, pp. 1234-1242, 2007.

[13] M. Cicardi, B. Cesana, E. Del Ninno et al., "Prevalence and risk factors for the presence of serum cryoglobulins in patients with chronic hepatitis C," Journal of Viral Hepatitis, vol. 7, no. 2, pp. 138-143, 2000.

[14] F. Lunel, L. Musset, P. Cacoub et al., "Cryoglobulinemia in chronic liver diseases: Role of hepatitis C virus and liver damage," Gastroenterology, vol. 106, no. 5, pp. 1291-1300, 1994.

[15] P. Fallahi, A. di Domenicantonio, V. Mazzi et al., "Hepatitis c virus and type 1 diabetes," Clinica Terapeutica, vol. 164, no. 5, pp. e437-e444, 2013.

[16] P. Fallahi, S. M. Ferrari, M. Colaci et al., "Hepatitis C virus infection and type 2 diabetes," La Clinica Terapeutica, vol. 164, no. 5, pp. e393-e404, 2013.

[17] P. Obermayer-Straub and M. P. Manns, "Hepatitis C and $\mathrm{D}$, retroviruses and autoimmune manifestations," Journal of Autoimmunity, vol. 16, no. 3, pp. 275-285, 2001.

[18] D. S. A. McLeod and D. S. Cooper, "The incidence and prevalence of thyroid autoimmunity," Endocrine, vol. 42, no. 2, pp. 252-265, 2012.

[19] J. Orgiazzi, “Thyroid autoimmunity," La Presse Médicale, vol. 41, part 2, no. 12, pp. e611-e625, 2012.

[20] P. Caturegli, A. de Remigis, and N. R. Rose, "Hashimoto thyroiditis: clinical and diagnostic criteria," Autoimmunity Reviews, vol. 13, no. 4-5, pp. 391-397, 2014.
[21] A. Corrado, S. M. Ferrari, C. Ferri, E. Ferrannini, A. Antonelli, and P. Fallahi, "Type 1 diabetes and (C-X-C motif) ligand (CXCL) 10 chemokine," Clinica Terapeutica, vol. 165, no. 2, pp. e181-e185, 2014.

[22] C. Mancusi, A. di Domenicantonio, U. Politti et al., "The alpha chemokine "Interferon gamma-induced protein 10" (IP-10) in Graves' disease," Clinica Terapeutica, vol. 165, no. 2, pp. el74e180, 2014.

[23] L. Saranac, S. Zivanovic, B. Bjelakovic, H. Stamenkovic, M. Novak, and B. Kamenov, "Why is the thyroid so prone to autoimmune disease?" Hormone Research in Paediatrics, vol. 75, no. 3, pp. 157-165, 2011.

[24] G. A. Brent, "Environmental exposures and autoimmune thyroid disease," Thyroid, vol. 20, no. 7, pp. 755-761, 2010.

[25] Y. Tomer, "Genetic susceptibility to autoimmune thyroid disease: past, present, and future," Thyroid, vol. 20, no. 7, pp. 715$725,2010$.

[26] L. H. Duntas, "Environmental factors and thyroid autoimmunity," Annales d'Endocrinologie, vol. 72, no. 2, pp. 108-113, 2011.

[27] E. Martino, E. Macchia, F. Aghini-Lombardi et al., "Is humoral thyroid autoimmunity relevant in amiodarone iodine-induced thyrotoxicosis (AIIT)?” Clinical Endocrinology, vol. 24, no. 6, pp. 627-633, 1986.

[28] J. Köhrle, "Selenium and the thyroid," Current Opinion in Endocrinology, Diabetes and Obesity, vol. 20, no. 5, pp. 441-448, 2013.

[29] A. Antonelli, C. Ferri, and P. Fallahi, "Hepatitis C: thyroid dysfunction in patients with hepatitis C on IFN- $\alpha$ therapy," Nature Reviews Gastroenterology and Hepatology, vol. 6, no. 11, pp. 633-635, 2009.

[30] R. Desailloud and D. Hober, "Viruses and thyroiditis: an update," Virology Journal, vol. 6, article 5, 2009.

[31] N. Akeno, J. T. Blackard, and Y. Tomer, "HCV E2 protein binds directly to thyroid cells and induces IL- 8 production: a new mechanism for HCV induced thyroid autoimmunity," Journal of Autoimmunity, vol. 31, no. 4, pp. 339-344, 2008.

[32] R. Minelli, L. E. Braverman, T. Giuberti et al., "Effects of excess iodine administration on thyroid function in euthyroid patients with a previous episode of thyroid dysfunction induced by interferon-alpha treatment," Clinical Endocrinology, vol. 47, no. 3, pp. 357-361, 1997.

[33] Y. Tomer and T. F. Davies, "Infection, thyroid disease, and autoimmunity, Endocrine Reviews, vol. 14, no. 1, pp. 107-120, 1993.

[34] J. Bartolomé, E. Rodríguez-Iñigo, P. Quadros et al., "Detection of hepatitis $\mathrm{C}$ virus in thyroid tissue from patients with chronic HCV infection," Journal of Medical Virology, vol. 80, no. 9, pp. 1588-1594, 2008.

[35] V. Agnello and F. G. De Rosa, "Extrahepatic disease manifestations of HCV infection: some current issues," Journal of Hepatology, vol. 40, no. 2, pp. 341-352, 2004.

[36] J. C. Duclos-Vallée, C. Johanet, J. C. Trinchet et al., "High prevalence of serum antibodies to hepatitis $\mathrm{C}$ virus in patients with Hashimoto's thyroiditis," British Medical Journal, vol. 309, no. 6958, pp. 846-847, 1994.

[37] R. Yang, Z. Shan, Y. Li, C. Fan, C. Li, and W. Teng, "Prevalence of thyroid autoantibodies in hepatitis $\mathrm{C}$ and hepatits $\mathrm{B}$ infection in China," Internal Medicine, vol. 50, no. 8, pp. 811-815, 2011.

[38] M. L. Marconcini, L. Fayad, M. B. C. Shiozawa, E. B. DantasCorrea, L. de Lucca Schiavon, and J. L. Narciso-Schiavon, "Autoantibody profile in individuals with chronic hepatitis C," 
Revista da Sociedade Brasileira de Medicina Tropical, vol. 46, no. 2, pp. 147-153, 2013.

[39] L. Fernandez-Soto, A. Gonzalez, F. Escobar-Jimenez et al., "Increased risk of autoimmune thyroid disease in hepatitis C vs hepatitis B before, during, and after discontinuing interferon therapy," Archives of Internal Medicine, vol. 158, no. 13, pp. 14451448, 1998.

[40] D. L. S. Danilovic, M. C. Mendes-Correa, M. C. Chammas, H. Zambrini, R. K. Barros, and S. Marui, "Thyroid disturbance related to chronic hepatitis C infection: role of CXCL10," Endocrine Journal, vol. 60, no. 5, pp. 583-590, 2013.

[41] A. Antonelli, C. Ferri, A. Pampana et al., "Thyroid disorders in chronic hepatitis C," The American Journal of Medicine, vol. 117, no. 1, pp. 10-13, 2004.

[42] M. Rodríguez-Torres, C. F. Ríos-Bedoya, G. Ortiz-Lasanta, A. M. Marxuach-Cuétara, and J. Jiménez-Rivera, "Thyroid dysfunction (TD) among chronic hepatitis $\mathrm{C}$ patients with mild and severe hepatic fibrosis," Annals of Hepatology, vol. 7, no. 1, pp. 72-77, 2008.

[43] S. Ferri, L. Muratori, M. Lenzi, A. Granito, F. B. Bianchi, and D. Vergani, "HCV and autoimmunity," Current Pharmaceutical Design, vol. 14, no. 17, pp. 1678-1685, 2008.

[44] F. Menconi, A. Hasham, and Y. Tomer, "Environmental triggers of thyroiditis: hepatitis C and interferon- $\alpha$," Journal of Endocrinological Investigation, vol. 34, no. 1, pp. 78-84, 2011.

[45] A. Testa, P. Castaldi, V. Fant et al., "Prevalence of HCV antibodies in autoimmune thyroid disease," European Review for Medical and Pharmacological Sciences, vol. 10, no. 4, pp. 183186, 2006.

[46] A. Antonelli, C. Ferri, S. M. Ferrari, M. Colaci, D. Sansonno, and P. Fallahi, "Endocrine manifestations of hepatitis $\mathrm{C}$ virus infection," Nature Clinical Practice Endocrinology and Metabolism, vol. 5, no. 1, pp. 26-34, 2009.

[47] R. A. Metcalfe, G. Ball, G. Kudesia, and A. P. Weetman, "Failure to find an association between hepatitis $C$ virus and thyroid autoimmunity," Thyroid, vol. 7, no. 3, pp. 421-424, 1997.

[48] J. Boadas, J. Rodriguez-Espinosa, J. Enriquez et al., "Prevalence of thyroid autoantibodies is not increased in blood donors with hepatitis C virus infection," Journal of Hepatology, vol. 22, no. 6 , pp. 611-615, 1995.

[49] N. Ganne-Carrie, A. Medini, E. Coderc et al., "Latent autoimmune thyroiditis in untreated patients with $\mathrm{HCV}$ chronic hepatitis: a case-control study," Journal of Autoimmunity, vol. 14, no. 2, pp. 189-193, 2000.

[50] L. Donati, A. Antonelli, F. Bertoni et al., "Clinical picture of endemic cretinism in central Apennines (Montefeltro)," Thyroid, vol. 2, no. 4, pp. 283-290, 1992.

[51] G. Indolfi, S. Stagi, E. Bartolini et al., "Thyroid function and anti-thyroid autoantibodies in untreated children with vertically acquired chronic hepatitis C virus infection," Clinical Endocrinology, vol. 68, no. 1, pp. 117-121, 2008.

[52] D. Pateron, D. J. Hartmann, J. C. Duclas-Vallee, H. Jouanolle, and M. Beaugrand, "Latent autoimmune thyroid disease in patients with chronic HCV hepatitis," Journal of Hepatology, vol. 16, no. 1-2, pp. 244-245, 1992.

[53] U. Watanabe, E. Hashimoto, T. Hisamitsu, H. Obata, and N. Hayashi, "The risk factor for development of thyroid disease during interferon- $\alpha$ therapy for chronic hepatitis C," The American Journal of Gastroenterology, vol. 89, no. 3, pp. 399-403, 1994.

[54] C. Carella, G. Amato, B. Biondi et al., "Longitudinal study of antibodies against thyroid in patients undergoing interferon- $\alpha$ therapy for HCV chronic hepatitis," Hormone Research, vol. 44, no. 3, pp. 110-114, 1995.

[55] E. Roti, R. Minelli, T. Giuberti et al., "Multiple changes in thyroid function in patients with chronic active HCV hepatitis treated with recombinant interferon-alpha," The American Journal of Medicine, vol. 101, no. 5, pp. 482-487, 1996.

[56] M. Marazuela, L. García-Buey, B. González-Fernández et al., "Thyroid autoimmune disorders in patients with chronic hepatitis C before and during interferon- $\alpha$ therapy," Clinical Endocrinology, vol. 44, no. 6, pp. 635-642, 1996.

[57] C. Carella, G. Mazziotti, F. Morisco et al., "The addition of ribavirin to interferon- $\alpha$ therapy in patients with hepatitis $C$ virus-related chronic hepatitis does not modify the thyroid autoantibody pattern but increases the risk of developing hypothyroidism," European Journal of Endocrinology, vol. 146, no. 6, pp. 743-749, 2002.

[58] Z. L. Teng, W. J. Gong, S. Q. Zhang, Y. X. Sun, and X. H. Ma, "Clinical observation of Hashimoto thyroiditis in patients with chronic hepatitis $\mathrm{C}$ undergoing pegylated-interferon alpha-2a and ribavirin combination therapy," Zhonghua Ganzangbing Zazhi, vol. 21, no. 2, pp. 101-104, 2013.

[59] A. Antonelli, C. Ferri, P. Fallahi et al., "Thyroid disorders in chronic hepatitis C virus infection," Thyroid, vol. 16, no. 6, pp. 563-572, 2006.

[60] T. P. Giordano, L. Henderson, O. Landgren et al., "Risk of non-Hodgkin lymphoma and lymphoproliferative precursor diseases in US veterans with hepatitis C virus," The Journal of the American Medical Association, vol. 297, no. 18, pp. 2010-2017, 2007.

[61] A. Antonelli, C. Ferri, M. Galeazzi et al., "HCV infection: pathogenesis, clinical manifestations and therapy," Clinical and Experimental Rheumatology, vol. 26, no. 1, supplement 48, pp. S39-S47, 2008.

[62] Z. Y. Mohran, N. A. Abdel Kader, A. T. Abdel Moez, and A. A. Abbas, "Subclinical autoimmune thyroid disorders in Egyptian patients with untreated chronic hepatitis C virus infection," Journal of the Egyptian Society of Parasitology, vol. 40, no. 1, pp. 45-56, 2010.

[63] M. W. Russo and M. W. Fried, "Side effects of therapy for chronic hepatitis C," Gastroenterology, vol. 124, no. 6, pp. 1711-1719, 2003.

[64] O. Dalgard, K. Bjøro, K. Hellum et al., "Thyroid dysfunction during treatment of chronic hepatitis $\mathrm{C}$ with interferon alpha: No association with either interferon dosage or efficacy of therapy," Journal of Internal Medicine, vol. 251, no. 5, pp. 400406, 2002.

[65] M. Friedrich-Rust, J. Theobald, S. Zeuzem, and J. Bojunga, "Thyroid function and changes in ultrasound morphology during antiviral therapy with pegylated interferon and ribavirin in patients with chronic hepatitis C," Journal of Viral Hepatitis, vol. 16, no. 3, pp. 168-177, 2009.

[66] I. S. Fentiman, B. S. Thomas, F. R. Balkwill, R. D. Rubens, and J. L. Hayward, "Primary hypothyroidism associated with interferon therapy of breast cancer," The Lancet, vol. 1, no. 8438, p. $1166,1985$.

[67] L. J. de Oliveira Andrade, A. D. Junior, C. A. Costa Silva et al., "A meta-analysis of patients with chronic hepatitis $C$ treated with interferon-alpha to determine the risk of autoimmune thyroiditis," Acta Gastroenterologica Latinoamericana, vol. 41, no. 2, pp. 104-110, 2011.

[68] H. A. Tran and G. E. M. Reeves, "The spectrum of autoimmune thyroid disease in the short to medium term following 
interferon-therapy for chronic hepatitis C," International Journal of Endocrinology, vol. 2009, Article ID 241786, 5 pages, 2009.

[69] L. K. H. Koh, F. S. Greenspan, and P. P. B. Yeo, "Interferon- $\alpha$ induced thyroid dysfunction: three clinical presentations and a review of the literature," Thyroid, vol. 7, no. 6, pp. 891-896, 1997.

[70] V. Wong, A. X.-L. Fu, J. George, and N. W. Cheung, "Thyrotoxicosis induced by alpha-interferon therapy in chronic viral hepatitis," Clinical Endocrinology, vol. 56, no. 6, pp. 793-798, 2002.

[71] J. C. Mandac, S. Chaudhry, K. E. Sherman, and Y. Tomer, "The clinical and physiological spectrum of interferon-alpha induced thyroiditis: Toward a new classification," Hepatology, vol. 43, no. 4, pp. 661-672, 2006.

[72] A. Czarnywojtek, M. Zgorzalewicz-Stachowiak, R. Waško et al., "Patients with chronic hepatitis type $\mathrm{C}$ and interferonalpha-induced hyperthyroidism in two-years clinical followup," Neuroendocrinology Letters, vol. 34, no. 2, pp. 154-161, 2013.

[73] L. J. D. O. Andrade, A. M. Atta, A. D’Almeida Jr., and R. Paranà, "Thyroid dysfunction in hepatitis $\mathrm{C}$ individuals treated with interferon-alpha and ribavirin-a review," Brazilian Journal of Infectious Diseases, vol. 12, no. 2, pp. 144-148, 2008.

[74] M. F. Prummel and P. Laurberg, "Interferon- $\alpha$ and autoimmune thyroid disease," Thyroid, vol. 13, no. 6, pp. 547-551, 2003.

[75] S. P. Savvas, N. Papakostas, M. Giannaris, S. Malaktari, J. Koskinas, and A. J. Archimandritis, "Interferon alpha-Induced hashimoto thyroiditis followed by transient graves disease in a patient with chronic HCV infection," Southern Medical Journal, vol. 103, no. 6, pp. 585-588, 2010.

[76] J. S. Mammen, S. R. Ghazarian, A. Rosen, and P. W. Ladenson, "Patterns of interferon-alpha-induced thyroid dysfunction vary with ethnicity, sex, smoking status, and pretreatment thyrotropin in an international cohort of patients treated for hepatitis C," Thyroid, vol. 23, no. 9, pp. 1151-1158, 2013.

[77] M. Goldman, P. Lambert, N. Tasiaux et al., “Thyroid-stimulating immunoglobulins in mixed (type II) cryoglobulinemia associated with thyrotoxicosis," Arthritis and Rheumatism, vol. 30, no. 11, pp. 1318-1319, 1987.

[78] A. Castellano Higuera, E. González Reimers, B. Alarcó Hernández, F. Santolaria Fernández, and M. Rodríguez Gaspar, "Hypotiroidism, hemolytic anemia and cryoglobulinemia in a patient with hepatitis $C$ virus infection: efficacy of treatment with alpha-interferon," Anales de Medicina Interna, vol. 20, no. 7, pp. 391-392, 2003.

[79] A. Antonelli, C. Ferri, P. Fallahi et al., "High values of CXCL10 serum levels in mixed cryoglobulinemia associated with hepatitis C infection," The American Journal of Gastroenterology, vol. 103, no. 10, pp. 2488-2494, 2008.

[80] A. Antonelli, C. Ferri, P. Fallahi et al., “Thyroid involvement in patients with HCV-related mixed cryoglobulinaemia," QJM, vol. 97, no. 8, pp. 499-506, 2004.

[81] A. Antonelli, C. Ferri, and P. Fallahi, "Thyroid cancer in patients with hepatitis C infection," Journal of the American Medical Association, vol. 281, no. 17, p. 1588, 1999.

[82] M. Montella, A. Crispo, L. Pezzullo et al., "Is hepatitis C virus infection associated with thyroid cancer? A case-control study," International Journal of Cancer, vol. 87, no. 4, pp. 611-612, 2000.

[83] M. Montella, A. Crispo, G. de Bellis et al., "HCV and cancer: a case-control study in a high-endemic area," Liver, vol. 21, no. 5, pp. 335-341, 2001.
[84] A. Antonelli, C. Ferri, P. Fallahi, C. Nesti, A. L. Zignego, and M. Maccheroni, "Thyroid cancer in HCV-related mixed cryoglobulinemia patients," Clinical and Experimental Rheumatology, vol. 20, no. 5, pp. 693-696, 2002.

[85] E. Fiore, T. Rago, F. Latrofa et al., "Hashimoto's thyroiditis is associated with papillary thyroid carcinoma: role of TSH and of treatment with L-thyroxine," Endocrine-Related Cancer, vol. 18, no. 4, pp. 429-437, 2011.

[86] M.-H. Lee, H.-I. Yang, S.-N. Lu et al., "Chronic hepatitis C virus infection increases mortality from hepatic and extrahepatic diseases: a community-based long-term prospective study," The Journal of Infectious Diseases, vol. 206, no. 4, pp. 469-477, 2012.

[87] A. Antonelli, C. Ferri, P. Fallahi et al., "Thyroid cancer in HCVrelated chronic hepatitis patients: a case-control study," Thyroid, vol. 17, no. 5, pp. 447-451, 2007.

[88] S. Neri, P. Boraschi, A. Antonelli, F. Falaschi, and L. Baschieri, "Pulmonary function, smoking habits, and high resolution computed tomography (HRCT) early abnormalities of lung and pleural fibrosis in shipyard workers exposed to asbestos," The American Journal of Industrial Medicine, vol. 30, no. 5, pp. 588595, 1996.

[89] A. Antonelli, P. Fallahi, S. M. Ferrari et al., "Dedifferentiated thyroid cancer: a therapeutic challenge," Biomedicine and Pharmacotherapy, vol. 62, no. 8, pp. 559-563, 2008.

[90] A. Antonelli, G. Bocci, C. La Motta et al., "Novel pyrazolopyrimidine derivatives as tyrosine kinase inhibitors with antitumoral activity in vitro and in vivo in papillary dedifferentiated thyroid cancer," The Journal of Clinical Endocrinology and Metabolism, vol. 96, no. 2, pp. E288-E296, 2011.

[91] A. Martocchia and P. Falaschi, "Amino acid sequence homologies between HCV polyprotein and thyroid antigens," Internal and Emergency Medicine, vol. 2, no. 1, pp. 65-67, 2007.

[92] Y. Tomer and R. Villanueva, "Hepatitis C and thyroid autoimmunity: is there a link?" The American Journal of Medicine, vol. 117, no. 1, pp. 60-61, 2004.

[93] Y. Tomer, J. T. Blackard, and N. Akeno, "Interferon alpha treatment and thyroid dysfunction," Endocrinology and Metabolism Clinics of North America, vol. 36, no. 4, pp. 1051-1066, 2007.

[94] R. Patzwahl, V. Meire, G. Ramadori, and S. Mihm, "Enhanced expression of interferon-regulated genes in the liver of patients with chronic hepatitis $\mathrm{C}$ virus infection: detection by suppression-subtractive hybridization," Journal of Virology, vol. 75, no. 3, pp. 1332-1338, 2001.

[95] S. Mihm, S. Schweyer, and G. Ramadori, "Expression of the chemokine IP-10 correlates with the accumulation of hepatic IFN- $\gamma$ and IL-18 mRNA in chronic hepatitis C but not in hepatitis B," Journal of Medical Virology, vol. 70, no. 4, pp. 562570, 2003.

[96] A. Antonelli, S. M. Ferrari, D. Giuggioli, E. Ferrannini, C. Ferri, and P. Fallahi, "Chemokine (C-X-C motif) ligand (CXCL)10 in autoimmune diseases," Autoimmunity Reviews, vol. 13, no. 3, pp. 272-280, 2014.

[97] A. Antonelli, S. M. Ferrari, A. Corrado, E. Ferrannini, and P. Fallahi, "CXCR3, CXCL10 and type 1 diabetes," Cytokine \& Growth Factor Reviews, vol. 25, no. 1, pp. 57-65, 2014.

[98] A. Antonelli, M. Rotondi, P. Fallahi et al., "Increase of interferon- $\gamma$-inducible CXC chemokine CXCL10 serum levels in patients with active Graves' disease, and modulation by methimazole therapy," Clinical Endocrinology, vol. 64, no. 2, pp. 189-195, 2006. 
[99] A. Antonelli, M. Rotondi, P. Fallahi et al., "Iodine-131 given for therapeutic purposes modulates differently interferon- $\gamma$ inducible $\alpha$-chemokine CXCL10 serum levels in patients with active Graves' disease or toxic nodular goiter," The Journal of Clinical Endocrinology and Metabolism, vol. 92, no. 4, pp. 14851490, 2007.

[100] A. Antonelli, P. Fallahi, M. Rotondi, S. M. Ferrari, M. Serio, and P. Miccoli, "Serum levels of the interferon- $\gamma$-inducible $\alpha$ chemokine CXCL10 in patients with active Graves'disease, and modulation by methimazole therapy and thyroidectomy," British Journal of Surgery, vol. 93, no. 10, pp. 1226-1231, 2006.

[101] A. Antonelli, M. Rotondi, P. Fallahi et al., "Increase of CXC chemokine CXCL10 and CC chemokine CCL2 serum levels in normal ageing," Cytokine, vol. 34, no. 1-2, pp. 32-38, 2006.

[102] A. A. Matskevich and D. S. Strayer, "Exploiting hepatitis C virus activation of $\mathrm{NF} \kappa \mathrm{B}$ to deliver HCV-responsive expression of interferons $\alpha$ and $\gamma$," Gene Therapy, vol. 10, no. 22, pp. 1861-1873, 2003.

[103] M. Murata, S. Nabeshima, N. Maeda, H. Nakashima, S. Kashiwagi, and J. Hayashi, "Increased frequency of IFN- $\gamma$-producing peripheral $\mathrm{CD}^{+} \mathrm{T}$ cells with memory-phenotype in patients with chronic hepatitis C," Journal of Medical Virology, vol. 67, no. 2, pp. 162-170, 2002.

[104] M. Loetscher, P. Loetscher, N. Brass, E. Meese, and B. Moser, "Lymphocyte-specific chemokine receptor CXCR3: regulation, chemokine binding and gene localization," European Journal of Immunology, vol. 28, no. 11, pp. 3696-3705, 1998.

[105] S. Qin, J. B. Rottman, P. Myers et al., "The chemokine receptors CXCR3 and CCR5 mark subsets of T cells associated with certain inflammatory reactions," The Journal of Clinical Investigation, vol. 101, no. 4, pp. 746-754, 1998.

[106] M. Rotondi, A. Rosati, A. Buonamano et al., "High pretransplant serum levels of CXCL10/IP-10 are related to increased risk of renal allograft failure," The American Journal of Transplantation, vol. 4, no. 9, pp. 1466-1474, 2004.

[107] C. Pupilli, S. Giannini, P. Marchetti et al., "Autoantibodies to CD38 (ADP-ribosyl cyclase/cyclic ADP-ribose hydrolase) in Caucasian patients with diabetes: effects on insulin release from human islets," Diabetes, vol. 48, no. 12, pp. 2309-2315, 1999.

[108] A. Antonelli, T. Tuomi, M. Nannipieri et al., "Autoimmunity to CD38 and GAD in type I and type II diabetes: CD38 and HLA genotypes and clinical phenotypes," Diabetologia, vol. 45, no. 9, pp. 1298-1306, 2002.

[109] A. Antonelli, G. Baj, P. Marchetti et al., "Human anti-CD38 autoantibodies raise intracellular calcium and stimulate insulin release in human pancreatic islets," Diabetes, vol. 50, no. 5, pp. 985-991, 2001.

[110] A. Antonelli, C. Ferri, P. Fallahi et al., "CXCL10 $(\alpha)$ and CCL2 $(\beta)$ chemokines in systemic sclerosis-a longitudinal study," Rheumatology, vol. 47, no. 1, pp. 45-49, 2008.

[111] A. Antonelli, P. Fazzi, P. Fallahi, S. M. Ferrari, and E. Ferrannini, "Prevalence of hypothyroidism and Graves disease in sarcoidosis," Chest, vol. 130, no. 2, pp. 526-532, 2006.

[112] M. Takeuchi, K. Oh-I, J. Suzuki et al., "Elevated serum levels of CXCL9/monokine induced by interferon- $\gamma$ and CXCL10/interferon- $\gamma$-inducible protein-10 in ocular sarcoidosis," Investigative Ophthalmology and Visual Science, vol. 47, no. 3, pp. 1063-1068, 2006.

[113] A. Antonelli, A. Delle Sedie, P. Fallahi et al., "High prevalence of thyroid autoimmunity and hypothyroidism in patients with psoriatic arthritis," Journal of Rheumatology, vol. 33, no. 10, pp. 2026-2028, 2006.
[114] A. Antonelli, P. Fallahi, A. D. Sedie et al., "High values of alpha (CXCL10) and beta (CCL2) circulating chemokines in patients with psoriatic arthritis, in presence or absence of autoimmune thyroiditis," Autoimmunity, vol. 41, no. 7, pp. 537-542, 2008.

[115] A. Antonelli, S. M. Ferrari, P. Fallahi et al., "Monokine induced by interferon $\gamma$ (IFN $\gamma$ ) (CXCL9) and IFN $\gamma$ inducible T-cell $\alpha$-chemoattractant (CXCL11) involvement in Graves' disease and ophthalmopathy: modulation by peroxisome proliferator-activated receptor- $\gamma$ agonists," The Journal of Clinical Endocrinology and Metabolism, vol. 94, no. 5, pp. 1803-1809, 2009.

[116] A. Antonelli, P. Fallahi, C. Nesti et al., "Anti-CD38 autoimmunity in patients with chronic autoimmune thyroiditis or Graves' disease," Clinical and Experimental Immunology, vol. 126, no. 3, pp. 426-431, 2001.

[117] A. Antonelli, P. Fallahi, M. Rotondi et al., "Increased serum CXCL10 in Graves'disease or autoimmune thyroiditis is not associated with hyper- or hypothyroidism per se, but is specifically sustained by the autoimmune, inflammatory process," European Journal of Endocrinology, vol. 154, no. 5, pp. 651-658, 2006.

[118] Y. Hiromatsu, D. Yang, T. Bednarczuk, I. Miyake, K. Nonaka, and Y. Inoue, "Cytokine profiles in eye muscle tissue and orbital fat tissue from patients with thyroid-associated ophthalmopathy," Journal of Clinical Endocrinology and Metabolism, vol. 85, no. 3, pp. 1194-1199, 2000.

[119] P. Romagnani, M. Rotondi, E. Lazzeri et al., "Expression of IP10/CXCL10 and MIG/CXCL9 in the thyroid and increased levels of IP-10/CXCL10 in the serum of patients with recent-onset Graves' Disease," The American Journal of Pathology, vol. 161, no. 1, pp. 195-206, 2002.

[120] A. Antonelli, M. Rotondi, S. M. Ferrari et al., "Interferon- $\gamma$ inducible $\alpha$-chemokine CXCL10 involvement in Graves' ophthalmopathy: modulation by peroxisome proliferator-activated receptor- $\gamma$ agonists," The Journal of Clinical Endocrinology and Metabolism, vol. 91, no. 2, pp. 614-620, 2006.

[121] E. J. Gowans, "Distribution of markers of hepatitis C virus infection throughout the body," Seminars in Liver Disease, vol. 20, no. 1, pp. 85-102, 2000.

[122] A. Antonelli, C. Ferri, P. Fallahi et al., " $\alpha$-Chemokine CXCL10 and $\beta$-chemokine CCL2 serum levels in patients with hepatitis $\mathrm{C}$-associated cryoglobulinemia in the presence or absence of autoimmune thyroiditis," Metabolism: Clinical and Experimental, vol. 57, no. 9, pp. 1270-1277, 2008.

[123] A. Antonelli, C. Ferri, S. M. Ferrari et al., "Interleukin-1 $\beta$, C-X$\mathrm{C}$ motif ligand 10, and interferon-gamma serum levels in mixed cryoglobulinemia with or without autoimmune thyroiditis," Journal of Interferon and Cytokine Research, vol. 30, no. 11, pp. 835-842, 2010.

[124] A. Antonelli, C. Ferri, S. M. Ferrari et al., "The presence of autoimmune thyroiditis in mixed cryoglobulinemia patients is associated with high levels of circulating interleukin-6, but not of tumour necrosis factor-alpha," Clinical and Experimental Rheumatology, vol. 29, no. 1, supplement 64, pp. S17-S22, 2011.

[125] E. Villa, A. Karampatou, C. Camm et al., "Early menopause is associated with lack of response to antiviral therapy in women with chronic hepatitis C," Gastroenterology, vol. 140, no. 3, pp. 818-829, 2011.

[126] M. Müller, S. L. Carter, M. J. Hofer et al., "CXCR3 signaling reduces the severity of experimental autoimmune encephalomyelitis by controlling the parenchymal distribution 
of effector and regulatory T cells in the central nervous system," Journal of Immunology, vol. 179, no. 5, pp. 2774-2786, 2007.

[127] P. Putheti, M. Morris, L. Stawiarz et al., "Multiple sclerosis: a study of chemokine receptors and regulatory $\mathrm{T}$ cells in relation to MRI variables," European Journal of Neurology, vol. 10, no. 5, pp. 529-535, 2003.

[128] L. N. Stiles, M. T. Liu, J. C. Kane, and T. E. Lane, "CXCL10 and trafficking of virus-specific T cells during coronavirus-induced demyelination," Autoimmunity, vol. 42, no. 6, pp. 484-491, 2009.

[129] G. Wildner and U. Kaufmann, "What causes relapses of autoimmune diseases? The etiological role of autoreactive T cells," Autoimmunity Reviews, vol. 12, no. 11, pp. 1070-1075, 2013. 


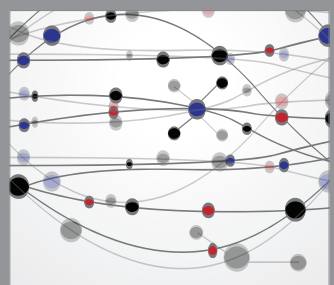

The Scientific World Journal
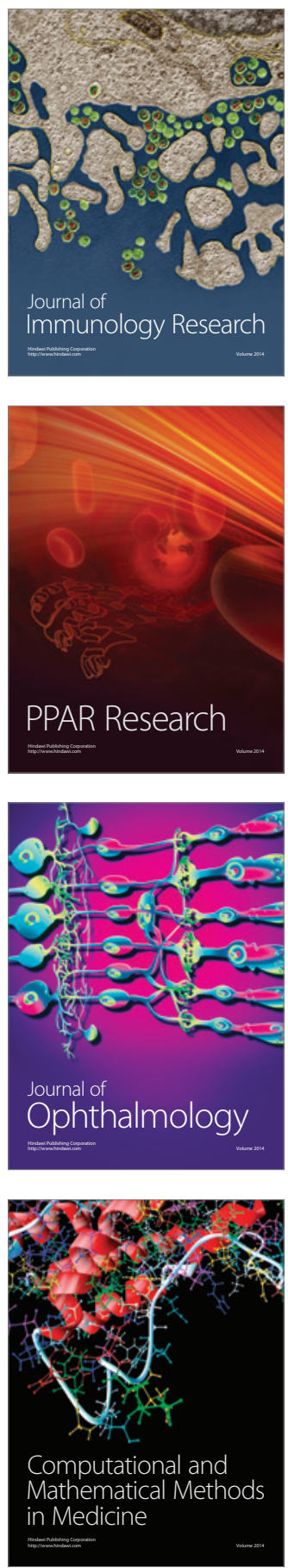

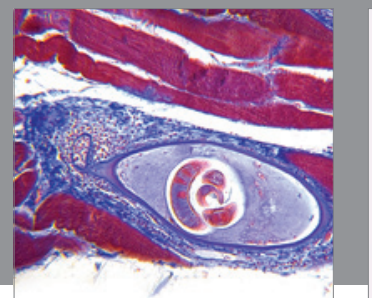

Gastroenterology

Research and Practice
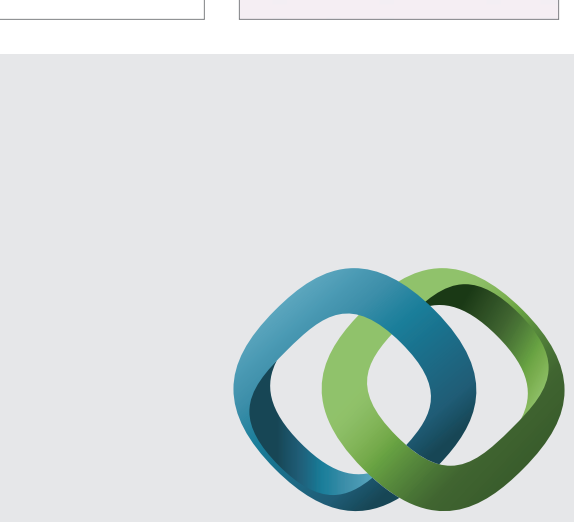

\section{Hindawi}

Submit your manuscripts at

http://www.hindawi.com
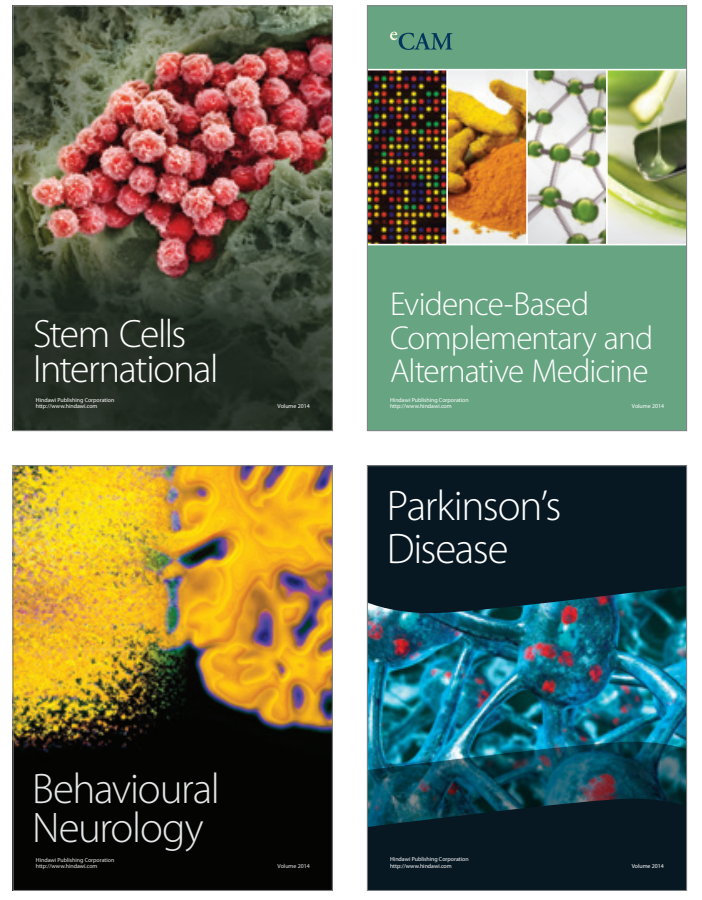
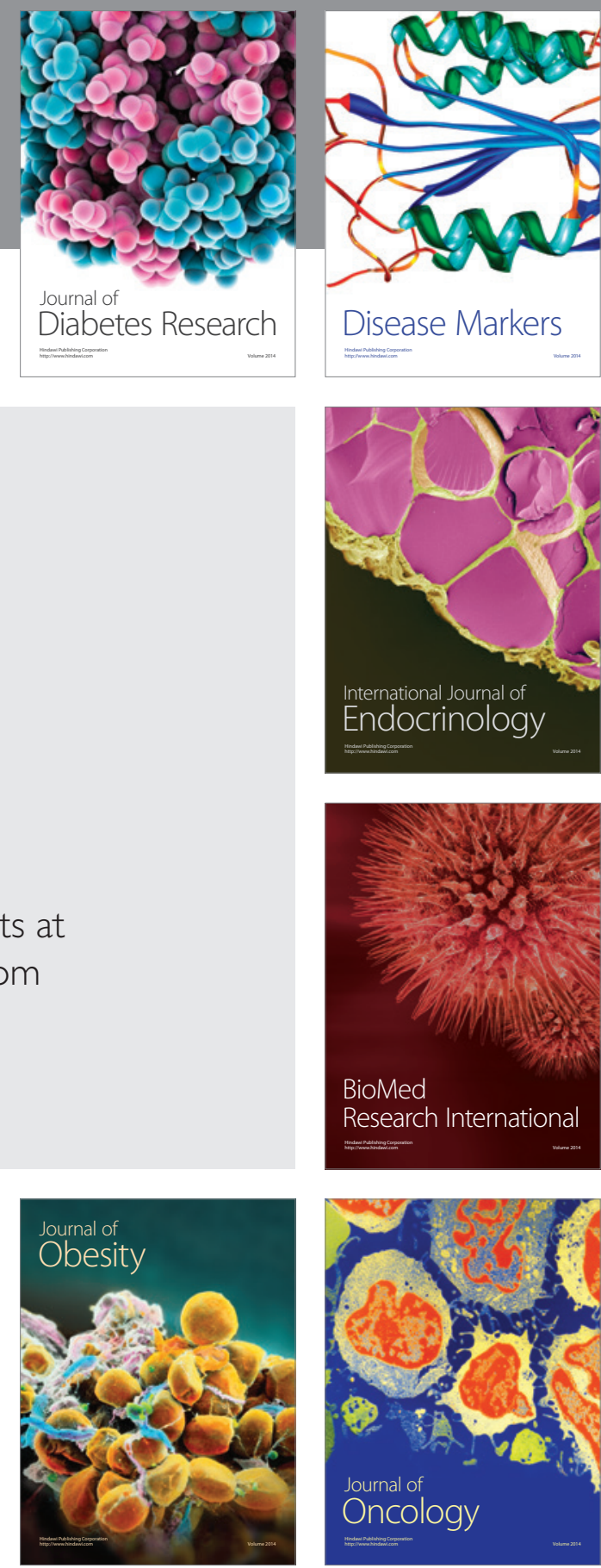

Disease Markers
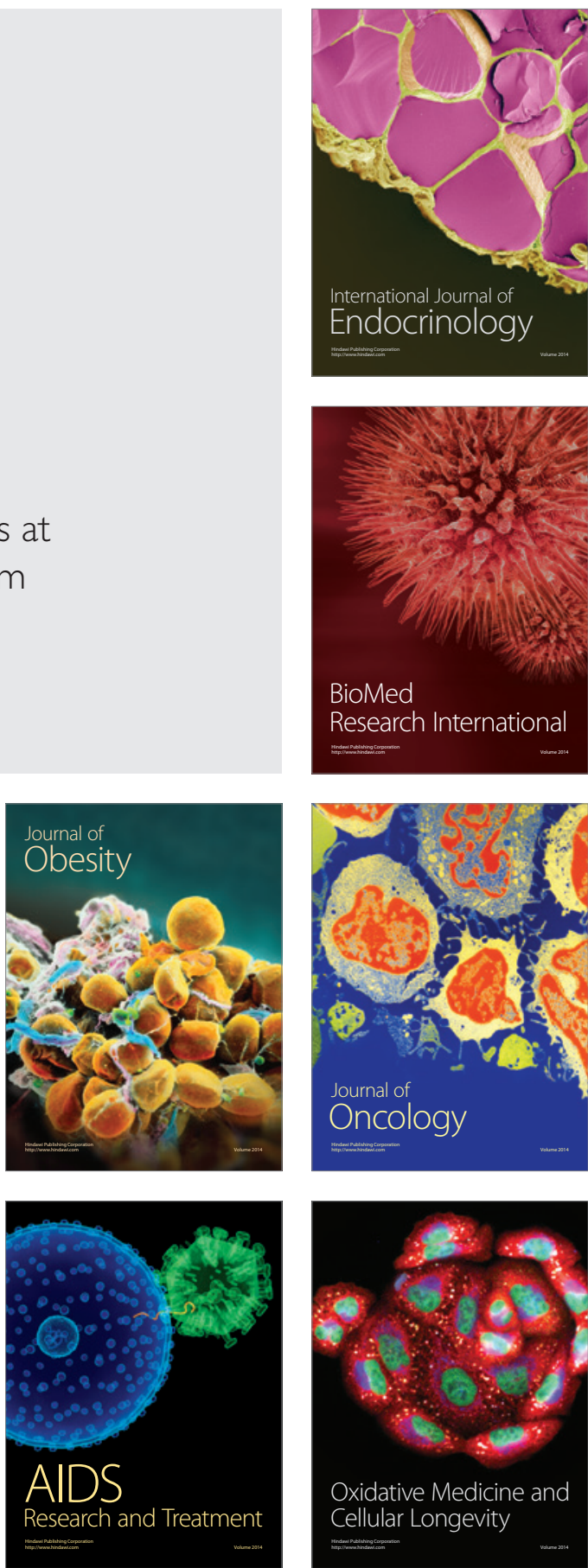